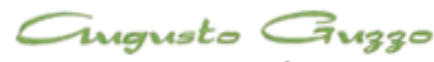

REVISTA ACADEMICA

\title{
A eficácia da participação do conselho de segurança da ONU na resolução do conflito de Darfur
}

\author{
Daniela Bertotti ${ }^{1}$ \\ Recebido em: 06/09/2013. Aprovado em: 22/11/2013. Disponibilizado em: 20/12/2013
}

1. Daniela Bertotti, doutoranda pela Pontifícia Universidade Católica de São Paulo. Mestre em Direito Político e Econômico pela Universidade Presbiteriana Mackenzie. Professora de Direito Internacional nas Faculdades Integradas "Campos Salles".

\section{Resumo}

O presente artigo tem como objetivo analisar as posições do Conselho de Segurança da ONU referentes ao conflito que se instalou no ano de 2003 na região de Darfur, Sudão. Embora algumas Resoluções do Conselho de Segurança já tenham sido proferidas a respeito do tema desde então, a situação na região ainda se mostra institucionalmente instável e violenta para os que lá habitam. Dessa forma, a intenção do texto que segue é ponderar o contexto histórico em que está inserido o conflito, seus principais atores e o papel dos Estados e dos Organismos Internacionais na tutela de direitos internacionalmente reconhecidos, além da própria efetividade dessas ações no plano da responsabilidade internacional.

Palavras-chave: Conflito de Darfur. Conselho de Segurança. Responsabilidade Internacional.

\begin{abstract}
This article aims to analyze the position of the UN Security Council for the conflict that was installed in 2003 in the Darfur region, Sudan. Some Resolutions of the Security Council have been made on the subject since then, although the situation in the region still shows up institutionally unstable and violent for those who live there. Thus, the intent of the text that follows is to consider the historical context in which it appears the conflict, their main actors and the role of states and international organizations in the protection of recognized internationally rights and the actual effectiveness of these actions in terms of international responsibility.
\end{abstract}

Keywords: Conflict of Darfur. Security Council. International Responsibility 


\section{Introdução}

A pesquisa versará a partir das considerações iniciais, do o histórico do conflito na região de Darfur no Sudão, da atuação do conselho de segurança no conflito de Darfur, da responsabilidade internacional dos atores, das as incertezas em relação ao conflito, em direção a uma compreensão satisfatória do conflito.

A observação da realidade africana por meio de uma análise de valores e estruturas ocidentais pode demonstrar-se questionável devido à especificidade de todo o modelo de colonização e estrutura de poder que lá se observa. Contudo, os países africanos, dentro do contexto internacional, têm direitos e deveres que recaem sobre qualquer nação chamada soberana.

A sedimentação de direitos internacionalmente protegidos pelos organismos internacionais, como as Nações Unidas e, mais especificadamente, a proteção da segurança e paz internacionais que recaem na competência do Conselho de Segurança, tem colocado alguns países da África no foco das discussões acerca do futuro do continente.

Como pano de fundo dessa temática está, sem dúvida, a discussão do papel do direito internacional e dos organismos de proteção da paz e segurança internacionais. $\mathrm{Ou}$ seja, em que medida as resoluções proferidas pelo Conselho de Segurança são eficazes na promoção daquilo que se propõem.

Há, sem dúvida, uma tentativa ocidental de entender o que se passa naquele complexo contexto em que a comunidade internacional é chamada a observar o que se passa dentro do continente africano e, principalmente, repudiar as agressões aos direitos humanos que podem ser observadas nos relatos que nos chegam acerca dos conflitos que se passam.

Talvez o estudo mais simples na tentativa de analisar a África seja ponderar que, devido à dificuldade, quase que intransponível, de diálogo entre as diversas etnias e religiões, o continente seja um campo fadado à incompreensão cuja superação beira o improvável e a ajuda se mostra um desafio.

Ora, não podemos fazer uma leitura tão rasa, uma vez que se isso fosse uma verdade em si mesma assinaríamos, além de uma sentença de preconceito, a incompetência dos africanos em dialogar e, mais, temeríamos que os países que receberam um número muito grande de imigrantes estariam na iminência de sofrer uma desestruturação social e política por conta desse fato histórico.

Os conflitos no continente africano não se apresentam de forma irracional e passional. Pode-se vislumbrar um ativismo político e econômico em que a etnia e a religião têm participação, mas não definem em si o núcleo da mobilização. Mesmo porque a construção de uma identidade nacional ainda mostra-se deficitária no contexto africano que estudaremos, a saber, Darfur.

Assim, compete assinalar que supostas razões comumente levantadas para estudar os conflitos na África não valem de seriedade acadêmica, tratam-se de mitos que se perpetuaram ao longo da história complexa e conflituosa naquele continente.

O conflito que será estudado no presente artigo é conhecido como "Conflito de Darfur", que acontece na região que leva o mesmo nome, no oeste do Sudão. Referido conflito chama atenção da comunidade internacional que, por meio de resoluções do Conselho de Segurança da ONU, encontra, em parte, a tradução da preocupação acerca 
da instabilidade que pode ser vislumbrada na região.

Faz-se necessário ressaltar que os números apresentados no decorrer do trabalho podem ser questionáveis e não poderia ser diferente. O governo do Sudão não disponibiliza dados oficiais que trazem credibilidade já que os próprios observadores da ONU não têm livre acesso a região e, por vezes, sofrem retaliações dos grupos armados. $^{1}$

De toda sorte, procurar-se-á trazer ao texto o cuidado em apresentar números que possam ter sua fonte sopesada a fim de perceber a confiabilidade do método. Além disso, relatórios da ONU e Resoluções do Conselho de Segurança nos ajudarão a dimensionar o conflito e a pesquisa histórica servirá para dar embasamento à realidade que se apresenta. Por fim, um estudo será feito acerca do viés jurídico do problema com ênfase no direito internacional público, especialmente, no que diz respeito à responsabilidade internacional dos atores envolvidos.

\section{O Histórico do Conflito na Região de Darfur no Sudão}

Sudão, país africano com cerca de 34 milhões de habitantes ${ }^{2}$, maior país da África, concentra, assim como nos demais países africanos, uma diversidade étnico-religiosa bastante numerosa, substratos estes que dão forma ao continente africano.

Não é pela reserva de petróleo que o país tem ocupado espaço na pauta internacional, mas, sim, pela guerra civil que assola o Estado sudanês desde a sua independência em 1956. O Sudão tornou-se independente do domínio britânico e seu governo foi assumido por representantes da população muçulmana que é acusada de tentar estabelecer os padrões e valores religiosos dentro da vida política do país.

Darfur, região localizada no oeste do Sudão, caracteriza-se pelo baixo nível de desenvolvimento e tornou-se foco de preocupação humanitária pelo conflito que se perpetua na região, oficialmente, desde 2003, não se confundindo, portanto, com as demais guerras que já tomaram conta do país em outros tempos. Alguns dados podem nos ajudar a entender a precariedade do povo da região:

\footnotetext{
1 Como exemplo, apresenta-se a seguinte notícia publicada no site da ONU: "Quatro capacetes azuis foram mortos e oito feridos numa emboscada contra uma patrulha militar nigeriana que servia à Missão Conjunta das Nações Unidas e da União Africana em Darfur (UNAMID), no Sudão. O ataque ocorreu na noite de ontem (2) próximo da sede da UNAMID em El Geneina, no oeste de Darfur. A Missão condenou o ataque. 'A Missão condena nos termos mais fortes este ataque criminoso contra 'nossas forças de paz, que estão aqui a serviço do povo de Darfur", disse o Comandante das Forças da UNAMID e atual funcionário responsável pelas
}

tropas, Patrick Nyamvumba. A UNAMID é encarregada de proteger os civis, promovendo um processo de paz inclusivo e ajudando a garantir a entrega segura de assistência humanitária na região. $\mathrm{O}$ local tem sido desde 2003 palco de combates entre tropas do governo sudanês e suas milícias aliadas contra rebeldes." Notícia publicada em 03 de outubro de 2012. Disponível em: <http://www.onu.org.br /onu-condena-emboscada-contra-capacetes-azuisem-darfur/>. Acesso em: 26.jun.13.

2 Informação disponível em <http://www. portasabertas.org.br/cristaosperseguidos/perfil/suda o/>. Acesso em: 23.jun.2013. 


\begin{tabular}{|c|c|c|}
\hline Fatores & Ano 2005 & Ano 2006 \\
\hline Acesso à água potável & $63 \%$ & $72 \%$ \\
\hline $\begin{array}{c}\text { Taxa de má nutrição das crianças } \\
\text { menores de 5 anos }\end{array}$ & $11,9 \%$ & $13,1 \%$ \\
\hline Insegurança Alimentar & $70 \%$ & $74 \%$ \\
\hline $\begin{array}{c}\text { Acesso adequado a alimentos } \\
\text { (pessoas que vivem em campos de deslocados }\end{array}$ & $36 \%$ & $14 \%$ \\
\hline
\end{tabular}

Fonte: PORDARFUR. Disponível em: <http://www.pordarfur.org/pt/go/dados-darfur>. Acesso em: 26.jun.13.

O conflito armado na região de Darfur apresenta como protagonistas a milícia Janjaweed, tribos nômades de língua árabe e religião muçulmana e os povos não-árabes da região. (BADMUS, 2008, p. 331)

O governo sudanês situado na capital Cartum providencia armamento e comanda o grupo Janjaweed, as ações de tal milícia têm resultado em incêndios e pilhagens de vilas, estupros de mulheres e assassinato de homens. Essa ideia de massacre do povo nãoárabe traz a tona a questão de "limpeza étnica”, ou, genocído. (BADMUS, 2008, p. 332)

Oficialmente, o conflito em questão teve início em 2003 quando um grupo de rebeldes de Darfur atacou postos do governo sudanês na região, entretanto, sabe-se que a crise está ligada a falta de recursos repassados pelo governo sudanês à Darfur que se mostra carente de infraestrutura. Esclareça-se, pois, que a demanda não se trata de um conflito entre muçulmanos e não muçulmanos, mas, sim, de uma insatisfação com a política interna do país, ganhando, assim, traços de conflitos econômicos e o estabelecimento de relações próximas com países que vendem armas aos grupos ou compram o petróleo do Sudão injetando, assim, dinheiro na economia do país. (MOTCHI, p. 08)

Diante dessa situação de instabilidade na região, o governo foi responsável pelo bombardeio aéreo em apoio aos ataques da milícia Janjaweed. Por conta dos massacres ocorridos na região desde o início dos ataques, um deslocamento de darfunianos ao Chade ou aos campos de refugiados que estão cercados por forças da milícia Janjaweed têm ocorrido. (LUIGI, 2008, p. 05)

Dados apontam que cerca de $250 \mathrm{mil}$ sudaneses já se deslocaram para o Chade que possui uma configuração étnica semelhante à da população de Darfur. Ocorre que tal mobilidade causou ao Chade a experiência de ataques em 2006. Esses ataques são realizados por grupos insurgentes árabes chadianos que recebem apoio do Sudão causando instabilidade entre o Chade e outros países vizinhos. (LUIGI, 2008, p. 03)

Fato é que a identidade nacional é um ponto frágil nesse contexto em que os indivíduos voltam a se identificar com suas comunidades menores, não havendo a construção de uma identidade nacional forte que sobreponha àquela das tribos. Assim, em termos de solução política e da procura pela legitimidade das decisões há uma disputa constante do poder que não passa por um processo democrático, mas, apenas pela ideia de dominação com fundamentos autoritários.

Atentos às carências da região, em 2007, uma operação híbrida entre a União Africana e as Nações Unidas, deu ensejo à UNAMID (African Union/United Nations Hybrid operation in Darfur), de acordo com a aprovação da Resolução 1769 do Conselho de Segurança.

La UNAMID tiene como principal mandato la protección de los civiles, así como contribuir a la seguridad en 
relación con la asistencia humanitaria, vigilar y verificar la aplicación de los acuerdos, ayudar a conseguir un proceso político inclusivo, contribuir a promover los derechos humanos y el estado de derecho, y vigilar la situación a lo largo de las fronteras con el Chad y la República Centroafricana e informar al respecto. ${ }^{3}$

A obtenção de informações idôneas na região mostra-se bastante prejudicada por conta do golpe de estado articulado em 1989; de toda sorte, a UNAMID estima que cerca de 4.7 milhões de pessoas em Darfur sejam afetadas pelo conflito, em uma população total na região de cerca de 6 milhões de pessoas. 4

Omar Hassan Ahmad Al-Bashir, chefe do Poder Executivo sudanês, teve assunção ao poder por meio de um golpe de estado articulado em 1989. Recai sobre ele um mandado de prisão expedido em 2009 pelo Tribunal Penal Internacional por sustentada acusação da prática de genocídio na região de Darfur. 5

A situação em Darfur mostra-se bastante caótica, a luta entre os movimentos rebeldes e o governo ainda está no centro da discussão. $\mathrm{O}$ governo sudanês tem dificultado o diálogo com a comunidade internacional não aceitando de forma responsável os grupos humanitários, bem como, recusa-se a processar e enviar ao Tribunal Penal Internacional indivíduos

\footnotetext{
3 Informação disponível em <http://www.un.org/es/peacekeeping/missions/un amid/index.shtml>. Acesso em: 23.jun.13.

${ }^{4}$ Dados disponíveis em

$<$ http://www.savedarfur.org/pages/primer $>$. Acesso em: 23.jun.13.

5 "The decision to issue the warrant of arrest follows an Application made by the Prosecutor of the ICC, Luis Moreno-Ocampo on 14 July 2008. In its decision of 4 March 2009, the Pre-Trial Chamber indicted alBashir as an indirect (CO-) perpetrator for five counts of crimes against humanity (murder, extermination, forcible transfer, torture, rape) and two counts of war
}

considerados responsáveis por crimes como o genocídio.

Em suma, o problema na região remonta, certamente, sua origem histórica entre os povos árabes e não árabes, muçulmanos e não muçulmanos. Porém, percebe-se que a situação toma contornos políticos e econômicos não podendo ser restringida a uma simples diferença irreconciliável de ascendência ou escolha religiosa.

\section{A Atuação do Conselho de Segurança no Conflito de Darfur}

Diante do quadro apresentado, a comunidade internacional, especialmente as Nações Unidas não puderam olvidar o que ocorre em Darfur. Dessa forma, o Conselho de Segurança da ONU desde 2004 tem emitido resoluções com vistas a propor medidas que viabilizem a efetivação de direitos internacionalmente reconhecidos e repugnando qualquer ato contrário ao disposto na carta da ONU.

O Conselho de Segurança da ONU tem sua determinação legal no capítulo VII da Carta das Nações Unidas (1945). Suas funções e atribuições estão dispostas no artigo 39 da referida Carta, a saber:

O Conselho de Segurança determinará a existência de qualquer ameaça à paz, ruptura da paz ou ato de agressão, e fará

crimes (direct attacks on civilians and pillaging). Although the majority of the Chamber found that the Prosecutor had failed to provide reasonable grounds to prove the specific intent required for Genocide, they found sufficient evidence to believe that al-Bashir coordinated a five-year counterinsurgency campaign, a "core component" of which was the unlawful and intentional direct attack of the Fur, Masalit and Zaghawa civilian population." Excerto disponível em: < http://www.haguejusticeportal.net/index.php?id= 9502>. Acesso em: 23.jun.13. 
recomendações ou decidirá que medidas deverão ser tomadas de acordo com os artigo $41^{6}$ e $42^{7}$, a fim de manter ou restabelecer a paz e a segurança internacionais.

Não obstante o papel exercido pelo Conselho de Segurança, em abril de 2005, fora assinado um acordo de cessar fogo em Ndjamena, cidade no país vizinho Chade. Naquela oportunidade, o governo do Sudão e os rebeldes subscreveram o documento em que as partes se comprometeram a unir esforços para estabelecer a paz em Darfur propondo um cessar fogo naquela região. Ocorre que tal acordo não fora respeitado pelas partes, assim, ainda em 2005, o Conselho de Segurança se pronunciou sobre a situação impondo determinadas condições ao governo do Sudão e aos rebeldes.

Respeitando o que estabelece a Carta da ONU (1945), quanto à competência e funções, veio ainda no ano de 2005, a Resolução 15918 afirmando que a situação no Sudão constitui uma ameaça para a paz e a segurança internacionais e que não poderia haver solução militar para conflito em Darfur, condenando o não cumprimento do Acordo de Cessar-Fogo de Ndjamena, restando, pois, ao Conselho de Segurança a determinação de

\footnotetext{
${ }^{6}$ Da Carta da ONU (1945), artigo 41 “O Conselho de Segurança decidirá sobre as medidas que, sem envolver o emprego de forças armadas, deverão ser tomadas para tornar efetivas suas decisões e poderá convidar os Membros das Nações Unidas a aplicarem tais medidas. Estas poderão incluir interrupção completa ou parcial das relações econômicas, dos meios de comunicação ferroviários, marítimos, aéreos, postais, telegráficos, radiofônicos, ou de qualquer espécie e o rompimento das relações diplomáticas".

${ }^{7}$ Da Carta da ONU (1945), artigo 42 "No caso de o Conselho de Segurança considerar que as medidas previstas no artigo 41 seriam ou demonstraram que são inadequadas, poderá levar e efeito, por meio das forças aéreas, navais ou terrestres, a ação que julgar necessária para manter ou restabelecer a paz e a segurança internacionais. Tal ação poderá compreender
}

medidas mais austeras para a alteração do status quo apresentado na região.

A questão que se propõe a discussão não é se o Conselho de Segurança agiu de forma adequada ou inadequada, tampouco, pode-se fazer um juízo de valor sobre as Resoluções do Conselho. Porém, a problemática reside na capacidade ou não de transformar uma realidade de preocupação internacional por meio da Resolução, ou seja, em que medida a Resolução apresenta-se como um instrumento transformador e caso não cumpra sua função, onde está $O$ problema?

O Conselho de Segurança decidiu, então, a respeito do Conflito em Darfur que tendo em vista o fracasso no comprometimento das partes em pôr fim ao conflito, que seria imposto àqueles responsáveis pelo desenvolvimento do caos na região, a proibição de viagens internacionais, bem como a congelamento de bens. Também previu o Conselho de Segurança que um monitoramento na região fosse feito com o intuito de apurar a correta implementação das medidas determinadas pela Resolução?. demonstrações, bloqueios e outras operações, por parte das forças aéreas navais ou terrestres dos Membros das Nações Unidas".

8 Membros do Conselho de Segurança que votaram a favor da Resolução 1591 (2005): França, Reino Unido, Estados Unidos, Argentina, Belize, Brasil, Dinamarca, Grécia, Japão, Filipinas, Romênia e Tanzânia. Membros se abstiveram: China, Rússia e Argélia. Disponível em:

http://www.un.org/sc/committees/1591/>. Acesso em: 26.jun.13.

9 CONSELHO DE SEGURANÇA. Resolução 1591 de 29 de março de 2005. Security Council Commitee established pursuant to Resolution 1591 (2005) concerning the Sudan. Disponível em: < http://www.un.org/sc/committees/1591/>. Acesso em: 26.jun.13. 
Em outras Resoluções, como a 1556 de $2004^{10}$ e 1954 de $2010^{11}$, ainda sobre a questão de Darfur, o Conselho solicitou aos países que não vendessem armas ou apoio às milícias e rebeldes além de reiterar às partes o compromisso assinado em Ndjamena. ${ }^{12}$

Assim, podemos vislumbrar que há, sem dúvida, uma preocupação do Conselho de Segurança a respeito da situação em Darfur, porém, não se trata da efetividade da decisão, mas da decisão em si. O Conselho em última instância não é um organismo jurídico, mas, sim, político.

As soluções passam não por uma Resolução do Conselho de Segurança, mas por uma identidade com o Direito em si e, mais especificadamente, com a força do Direito Internacional e o reconhecimento deste no plano interno. Não parece, contudo, que essa eficácia apresente-se no Sudão. As instituições internas ditas democráticas, de um país presidencialista, não apresentam-se fortes o suficiente para que possamos esperar uma atitude diversa da que vemos, uma

\footnotetext{
${ }^{10}$ Membros do Conselho de Segurança que votaram a favor da Resolução 1556 (2004): França, Rússia, Reino Unido, Estados Unidos, Argélia, Angola, Belize, Brasil, Chile, Alemanha, Filipinas, Romênia e Espanha. Membros que se abstiveram: China e Paquistão. Disponível em: < http://www.un.org/sc/ committees/1556/>. Acesso em: 26.jun.13.

${ }_{11}$ Membros do Conselho de Segurança que votaram a favor da Resolução 1545 (2010): França, Rússia, Reino Unido, Estados Unidos, Áustria, Bosnia e Herzegovina, Brasil, Gabão, Japão, Líbano, México, Nigéria, Turquia e Uganda. Membro que se absteve: China. Disponível em: < http://www.un.org/sc/ committees/1545/>. Acesso em: 26.jun.13.

12 Disponível em:

<http://www.sudantribune.com/spip.php?article457 44>. Acesso em: 26.jun.13.

13 Disponível em: <

http://www.haguejusticeportal.net/index.php?id=95 02>. Acesso em: 26.jun.13.

14 ONU. Organização das Nações Unidas. ONU e União Africana pedem que o Sudão facilite ajuda humanitária para $18 \mathrm{mil}$ pessoas em Darfur. Disponível em: < http://www.onu.org.br/onu-e-
}

disputa de poder baseada na opressão. Inclusive, ressalte-se, que o Tribunal Penal Internacional já se posicionou a respeito da situação e, inclusive, emitiu mandado de prisão para o atual chefe de estado sudanês ${ }^{13}$.

A própria instalação de uma missão humanitária no Sudão foi motivo de muita discussão entre o Estado sudanês e a ONU. De toda sorte, apenas em 2007 o governo sudanês concordou com o envio da missão que, mesmo em 2013 ainda tem dificuldade em ajudar no controle da violência posto que o acesso dos "capacetes azuis" não é facilitado pelo governo sudanês ${ }^{14}$.

Contudo, mesmo com todo o aparato em termos legais e institucionais, o direito internacional encontra seu obstáculo na própria organização institucional do Estado e, principalmente, nas estruturas encontradas no plano interno. Não há como ignorar esse diálogo inerente ao direito internacional.

No plano teórico, poderíamos chegar a utopia de apenas defender a teoria monista kelseniana15, porém, na prática, ainda

uniao-africana-pedem-que-sudao-facilite-ajudahumanitaria-para-18-mil-pessoas-em-darfur/ $>$. Acesso em: 24.jun.13.

$15 \mathrm{O}$ posicionamento de Hans Kelsen mostra-nos a defesa da teoria monista internacionalista: "O Direito internacional, que do ponto de vista do primado da ordem jurídica estadual - ou da soberania do Estado apenas vale na medida em que um Estado o reconhece como vinculante em relação a si, surge, por conseguinte, não como uma ordem jurídica supraestadual, e também não como uma ordem jurídica independente da própria ordem estadual, isolada em face desta, mas - na medida em que seja Direito como uma parte integrante da própria ordem jurídica estadual. Tem-se-lhe chamado 'Direito estadual externo', partindo da suposição de que regula as relações do Estado com o 'exterior', as suas relações com outros Estados”. (KELSEN, 1998, p. 373) “A concepção de que o Direito estadual e o Direito internacional são ordens jurídicas distintas uma da outra e independentes uma da outra na sua validade é essencialmente baseada na existência de conflitos insolúveis entre os dois. Uma análise mais aprofundada mostra, porém, que o que se considera como conflito 
percebemos que a identidade com as instituições internacionais é que a faz efetiva e eficaz. Então, como exigir e esperar tal comportamento de um Estado tão fragilizado como o Sudão? Sem dúvida a confiança que precisa ser estabelecida entre as partes com vistas ao mútuo apoio e desarmamento é bastante complexa e as incertezas nesse panorama não demonstram uma incompetência do Conselho de Segurança, ou seja, não se trata de uma inexecução de decisões; mas, sim, de um Estado de Direito ainda não construído.

\section{Responsabilidade Internacional dos Atores}

Analisando a situação proposta nesse artigo, poderíamos nos perguntar se há uma valoração da responsabilidade internacional pela influência que determinado Estado tem perante os demais.

No caso da África, começaríamos, por exemplo, pela política econômica difundida pelos Estados Unidos pós Guerra-Fria e a falência dos Estados africanos em segui-la de uma forma a trazer benefícios para a região.

Objetivamente, não parece seguro falar em grau de responsabilidade, uma vez que todos os Estados têm sua soberania e autonomia para dialogar com a comunidade internacional como desejarem. Entretanto, há uma expectativa a respeito de determinados posicionamentos dos Estados que desfrutam de uma influência maior no campo internacional - sejam por razões políticas ou econômicas e isso pode ser vislumbrado na Assembleia Geral da ONU ou na forma como os Estados votam dentro do Conselho

entre normas do Direito internacional e normas de um Direito estadual não é de forma alguma um conflito de normas, que tal situação pode ser descrita em de Segurança, sejam eles membros permanentes ou não.

Em outras palavras, a imputação de um ato ilícito, segundo o Direito Internacional, deve ser reparada por outro Estado contra o qual este ato foi cometido, ou seja, uma transgressão à norma de direito internacional. Porém, esta responsabilidade não pode ser flutuante de acordo com a influência deste Estado no mundo moderno, sob pena de insegurança dentro das relações internacionais.

Não há, na doutrina, um critério de gradação da responsabilidade, apenas deve-se analisar a presença dos elementos caracterizadores de uma relação em que seja necessária a "finalidade reparatória".

Sendo assim, em uma analise da realidade trazida no presente artigo, pode-se afirmar que a soberania de um Estado traz consigo a responsabilidade perante o Direito Internacional na efetivação e proteção dos direitos humanos.

A soberania como responsabilidade aponta para a consideração do Estado de direito democrático como valor transnacional. A mesma assenta no pressuposto de que a soberania que verdadeiramente conta, no plano internacional, é a soberania popular. (...) O combate à corrupção, a transparência governativa, a participação popular e o fortalecimento do poder judicial são pré-requisitos do aperfeiçoamento dos sistemas econômico e financeiro, do progresso humano e social e do desenvolvimento sustentado. (MACHADO, 2006, p. 215)

Sendo assim, na medida em que há a inobservância dos direitos e garantias respeitados dentro de um Estado, este poderá

proposições jurídicas que de modo algum se contradizem logicamente." (KELSEN, 1998, p. 366) 
- $\quad$ sim - $\quad$ ser responsabilizado internacionalmente não devendo sequer ser indagada a origem do fato se ocorreu com ou sem culpa devido a magnitude do direito lesionado, jus cogens.

Nesse caso o dano causado dirige-se a outro sujeito de direito internacional, ou seja, o próprio indivíduo. "A doutrina vem paulatinamente rendendo-se à evidência de que o indivíduo age na sociedade internacional, muitas vezes independentemente do Estado, começando a reconbecer na pessoa natural o caráter de sujeito internacional' (PORTELA, 2011, p. 157).

A própria figura da responsabilidade internacional não é pacificada na doutrina, de qualquer forma, apresentar-se-á o instituto levando em conta o marco teórico de Francisco Rezek: “O Estado responsável pela prática de um ato ilícito segundo o direito internacional deve ao Estado a que tal ato tenha causado dano uma reparação adequada" (REZEK, 2011, p. 315).

Ora, na medida em que o Estado sudanês não dá a devida proteção aos seus nacionais ou aos estrangeiros que lá se encontram, como, no caso, da missa UNAMID que lá se encontra, não podemos olvidar que há a figura da responsabilidade.

Muito se discute acerca da responsabilidade depender ou não da culpa, ou seja, se deveríamos adotar a teoria da culpa ou a teoria objetiva. Porém, crê-se que basta ter havido afronta a uma norma ao direito internacional. (REZEK, 2011, p. 315)

Esse tema mostra-se muito delicado posto que no caso há uma possibilidade de defesa por parte do governo sudanês em alegar que tais crimes constituem em crimes de guerra ou de atos inerentes ao Estado na manutenção da ordem. Entretanto, tal fundamento não encontra respaldo tendo em vista o número de afetados pelo conflito e a instabilidade que a região se encontra há uma década.
Toda a ordem jurídica pressupõe que os sujeitos de direito assumam a sua responsabilidade logo que os seus comportamentos produzam dano aos direitos e interesses dos outros sujeitos de direito. Por maioria de razão, o mesmo se passa na sociedade internacional na qual, em virtude da sua soberania, o Estado determina livremente as suas decisões, que se limitam pela liberdade igual dos outros Estados. A responsabilidade internacional dos Estados aparece como o mecanismo regulador essencial e necessário das relações mútuas.

(...) Devido ao seu papel operacional crescente, as organizações internacionais são igualmente susceptíveis de comprometer a sua responsabilidade internacional ou de procurar reparar os prejuízos sofridos pelos seus agentes ou por elas próprias, por facto dos Estados. Tratando-se de um fenômeno recente, as soluções têm sido recolhidas no direito costumeiro existente e são largamente inspiradas na perspectiva interestatal clássica, com algumas adaptações. É portanto possível apresentar o direito da responsabilidade internacional segundo uma atitude uniforme para todos os sujeitos de direito internacional, ainda que eles não sejam todos iguais". (DINH; DAILLER; PELLET, 2003, p. 776-777)

Dessa forma, apresenta-se que os Estados e as Organizações Internacionais ao não se esquivarem do problema e votarem seus pontos de vista a respeito do tema não podem ser condenados pela ineficiência das decisões prolatadas ou da ajuda oferecida. $\mathrm{O}$ problema no Sudão, como tem sido exposto no presente artigo, está ligado ao sujeito, indivíduo, e o Estado. 


\section{As Incertezas em Relação ao Conflito}

Diante da ineficácia dos acordos assinados e da não alteração do caos lá instalado, a questão da intervenção humanitária tornou-se uma pauta delicada na medida em que tal figura não traz consenso na doutrina. Seria a intervenção humanitária a quebra da regra geral do direito internacional da não-intervenção ${ }^{16}$ ?

Intervenção em direito internacional é a ingerência de um estado nos negócios peculiares, internos ou externos, de outro estado soberano com o fim de impor a este a sua vontade. A dúvida existente é saber se as medidas tomadas por uma organização internacional podem ser qualificadas como intervenção. Tratando-se de organização de que o estado seja membro e tenha aceito livremente o respectivo estatuto, como no caso das Nações Unidas, as medidas eventualmente tomadas pela organização não podem ser assim qualificadas. (ACCIOLY, 2010, p. 334)

Entretanto, no caso de uma intervenção humanitária o que se busca perceber é a necessidade de proteção das populações locais contra atos de crueldade ou em defesa dos direitos humanos violados.

Desde o início dos anos 90 cumpre assinalar a importância do Conselho de Segurança da ONU no sentido de determinar operações de uso de força armada para a proteção de direitos fundamentais; bem como, em um segundo momento da atuação do Tribunal Penal Internacional em processar àqueles responsáveis por crimes como: genocídio, crimes contra a humanidade e crimes de guerra (ACCIOLY, 2010, p. 336)

Apesar de ser inegável que o Sudão é um Estado soberano e que sua

\footnotetext{
${ }^{16}$ Sobre o assunto ver ACCIOLY, 2010, p. 323.
}

integridade territorial deva ser respeitada, a Comissão da ONU, reconhecendo que o Sudão tem o direito de tomar medidas para manter e restabelecer sua autoridade e para defender sua integridade territorial, mantém o posicionamento de que soberania implica responsabilidade e, assim, que o Sudão é requerido não só a respeitar o direito internacional, mas também a garantir que seja respeitado. (BADMUS, 2008, p.337)

As intervenções humanitárias implicam a superação do conceito de soberania, ainda tão arraigado no direito internacional; "a ação humanitária é vítima de certo grau de incompreensão por parcela da opinião pública, sensível pela crítica violenta das organizações humanitárias a respeito dessas ações" (ACCIOLY, 2010, p. 338).

De acordo com o histórico apresentado, não é de se esperar que os países aceitem de forma pacífica a intervenção de outros Estados naquele continente. Por essa razão, a União Africana em conjunto com a ONU desenvolvem um papel bastante importante, ainda que, por diversas vezes não tenha a recepção mais positiva possível.

A União Africana, bloco regional, instituído em 2001, tem participado ativamente do diálogo entre o povo darfuniano e a ONU. Quando criado o bloco teve caracterizado o seguinte objetivo:

acelerar o processo de integração regional; promover e consolidar a unidade do continente; fomentar a união, a solidariedade e a coesão; eliminar o flagelo dos conflitos; e habilitar a África a fazer face aos desenvolvimentos políticos, econômicos e sociais da ordem internacional ${ }^{17}$

${ }^{17}$ MINISTÉRIO DAS RELAÇÕES EXTERIORES. União Africana (UA). Disponível em: 
Apesar de objetivos bastante audaciosos e sem dúvida importantíssimos para a região, a União Africana que é composta por todos os Estados Africanos, exceto Marrocos, ainda lida com dificuldades na implementação das forças para superar a falta de recurso na região e a insurgência em alguns Estados africanos ${ }^{18}$.

No caso de Darfur a realidade é essa, há a participação da União Africana no processo de paz no Sudão, porém, há uma resistência por parte do próprio Estado na abertura de suas fronteiras e no apoio à missão, além de um problema de financiamento. No caso estudado nesse artigo, a ajuda veio da $\mathrm{ONU}$ proporcionando uma união de esforços e a criação da UNAMID, missão esta que permanece em Darfur até o presente ano.

Uma segunda analise que precisa ser feita é a construção da ideia de pertencimento a um Estado, a consolidação da ideia de povo. O Sudão ainda carece dessa unicidade. A construção de uma democracia passa por uma condição para que as decisões possam ser executadas. O pertencer a uma nação é indispensável para que haja a legitimidade do processo democrático e decisório, além, da alternância do poder; o que não ocorre no Sudão que sofre com um golpe de Estado há mais de 23 anos. Ou seja, a superação das identidades comunitárias é um dos caminhos para que no Sudão possa apresentar-se como Estado de Direito.

Uma terceira problemática levantada no caso do Sudão diz respeito ao processo de edificação das instituições formais do Estado, ou seja, o problema na região não diz respeito a um suposto antagonismo étnico

<http://www.itamaraty.gov.br/temas/mecanismosinter-regionais/uniao-africana $>$. Acesso em: 24.jun.13. ${ }^{18}$ Disponível em: <http://www.au.int/en/>. Acesso em: 26.jun.13.

${ }^{19}$ Sobre o referido tema: "Also of importance to peace restoration in Darfur is the need for the developed countries to refrain from indulging in the politics of oil, but rather allow the people to evolve efficient irreconciliável, mas, uma necessidade de superação dos códigos tribais ou de clãs e o fortalecimento da legitimidade do Estado, que, para tanto, precisa ser baseado em princípios e direitos claramente apresentados e não obscuros ou advindos de um golpe de Estado.

Ao elegerem o Estado como porta-voz oficial da população no contexto global, no entanto, não conseguiram resolver o maior problema: Como superar os interesses dos Estados (governos e detentores do poder) se todos se diferenciam entre si, e onde cada um procura, em primeiro lugar, atender às suas necessidades particulares, em detrimento dos demais? (MIYAMOTO, 2011, p.49)

Dentro da quarta questão a ser discutida está a ideia de crime de guerra ou genocídio. Segundo as provas colhidas e levadas ao Tribunal Penal Internacional a o crime contra a humanidade configura genocídio, ou seja, a morte deliberada de pessoas por pertencerem a uma determinada raça ou tribo ${ }^{19}$.

O estado continua a ser a 'unidade básica' de formulação e operação do direito internacional, sem adentrar a questão específica do reconhecimento de estado e de governo, mas caberá aos tempos futuros ver em que medida se vai resguardar a dignidade humana, no plano internacional. Diante da condição do ser humano como sujeito de direito internacional, não somente decorrente de boa vontade ou por 'aceitação', 'dispensa' ou favor estatal, mas intrinsecamente ligada à sua dignidade e se não à fonte, dever-se-ia lembrar o destinatário último de toda

means of exploiting their oil reserves and equitably distributing their resources for the benefits of all the rest of the citizens without any discrimination on the grounds of sex, race or religion. In addition to this, the international community must come up with immediate presently ravaging the children, women and the brutalized people due to the long period of the crisis." (EBEGBULEM, 2011, p. 75) 
norma jurídica. (ACCIOLY, 2010, pp. 344-345)

A criação da ONU em 1945 veio, em algum sentido, coibir que atrocidades como àquelas que ocorreram na II Guerra Mundial voltassem a figurar nas nações e não se pode atribuir à realidade do Sudão uma suposta ineficiência da ONU ou do Conselho de Segurança, conforme afirmou-se no decorrer do presente artigo.

\section{Considerações Finais}

Para entender a África é preciso um pouco mais do que narrações de diferenças culturais, religiosas ou linguísticas. Sem dúvida, a miscigenação faz parte do histórico do continente, e não só desse. Porém, o que se procurou demonstrar foi que a discussão acerca da instabilidade em Darfur passa por causas políticas e por inexistência, em parte, da própria estrutura estatal que poderia ser utilizada para dar tutela a uma comunidade castigada pela violência.

A questão no Sudão não passa apenas por uma intervenção humanitária ou por Resoluções do Conselho de Segurança. Entende-se a relevância, para a comunidade internacional, das decisões tomadas, todavia, se percebe que para uma decisão dessa tipo possa gerar seus frutos é necessário que o solo em que caia seja fértil e institucionalmente forte para aplicá-las, ou seja, que vislumbre nessas decisões um caminho para a solução do problema.

No Sudão, entretanto, não vemos esse tipo de preocupação. As decisões e as ações que vem de organismos internacionais, quando aceitas, não o são na sua integralidade, há empecilhos colocados seja pelo governo, seja pelos rebeldes. O diálogo interno é prejudicado pela forma como a justiça se manifesta em Darfur, como as igualdades são percebidas, ou, ainda mais, o que elas seriam.

O tratamento feito pela comunidade internacional demonstra que os Estados e as organizações internacionais são se olvidam de trabalhar com o problema, de dialogar com ele. Não há que se falar uma ineficácia do direito internacional ou das decisões do Conselho de Segurança ou da UNAMID, há, entretanto, uma superação ainda maior: o Estado.

Voltamos, então, a ideia de que o Estado e a questão da soberania ainda apresentam-se necessárias como forma de "pertencimento" e de tutela, porém, na falta de um Estado de Direito como resolver o problema? Aí, então, está a superação que o direito internacional precisa contemplar. Ao mesmo tempo em que a ideia de Estado é importante, ela também dificulta a intervenção em locais tão fragilizados e que acabam sufocando direitos e garantias fundamentais amplamente discutidos nas Nações Unidas.

Sem dúvida a comunidade internacional apresenta-se solidária e preocupada com todo o cenário, mas, apesar da intervenção humanitária não se pode chegar a conclusão que a melhor forma de incrementar o sistema institucional sudanês seria a imposição de regras organizacionais. $\mathrm{O}$ amadurecimento do Estado passa por um processo que não pode ser abreviado e que não pode ser imposto, caso contrário, apagaríamos a história e venderíamos a nossa como a única verdade.

\section{Referências Bibliográficas}

1. ACCIOLY, HILDEBRANDO; SILVA, G. E. do Nascimento e; CASELLA, Paulo

Borba. Manual de Direito Internacional Público. $18^{a}$ ed. São Paulo: Saraiva, 2010. 
2. BADMUS, Isiaka Alani. "Nosso Darfur, Darfur Deles": A Política Desviante do Sudão e a Nascente "Limpeza Étnica" em uma emergente Anarquia Africana. In: Contexto Internacional. Vol. 30. Maio/Agosto. Rio de Janeiro, 2008.

3. CONSELHO DE SEGURANÇA DAS NAÇÕES UNIDAS. Security Council Imposes Travel Ban, Assets Freeze On Those Impeding Peace Process In Darfur. Adopting Resolution 1591 (2005). Disponível em: $<$ http://www.un.org/News/Press/docs/20 05 /sc8346.doc.htm>. Acesso em: 01.abr.13. 4. DINH, Nguyen Quoc; DAILLER, Patrick; PELLET, Alain. Direito Internacional Público. 2a. ed. Lisboa: Calouste Gulbenkian. 2003.

5. EBEGBULEM, Joseph C. Nigeria and Conflict Resolution in Africa: The Darfur Experience. In: Civilizar. Volume XI. Julho/Dezembro. Colômbia. 2011.

6. KELSEN, Hans. Teoria pura do Direito. 6. ed. São Paulo: Martins Fontes, 1998.

7. LUIGI, Ricardo. A Insegurança Regional e o Conflito na Região de Darfur. In: Revista Intellector. Volume IV. Janeiro/Junho. Rio de Janeiro. 2008. Disponível em: $<$ www.revistaintellector.cenegri.org.br>. Acesso em: 20.mai.2013.
8. MACHADO, Jónatas E. M.. Direito Internacional: do paradigma clássico ao pós11 de setembro. $3^{a}$ ed. Coimbra: Coimbra, 2006.

9. MIYAMOTO, Shiguenoli. O Ideário da Paz em um Mundo Conflituoso. In: Paradigma das Relações Internacionais. Gilmar Antônio Bedin e outros (coords.). Ijuí: UniIjuí, 2011.

10. MOTHCI, Daniela Espindula. Crise em Darfur: Um caso de Intervenção Humanitária? Disponível em: $<$ http://www.maxwell.lambda.ele.pucrio.br/10132/10132.PDF>. Acesso em: 20.mai.13.

11. PORTELA, Paulo Henrique Gonçalves Portela. Direito Internacional Público e Privado. $3^{\mathrm{a}}$ ed. Salvador: JusPodium. 2011.

12. REZEK. Francisco. Direito Internacional Público: Curso Elementar. São Paulo: Saraiva, 2011.

13. SCHNEIDER, Luiza Galiazzi. As causas políticas do conflito no Sudão: Determinantes estruturais e estratégicos. Disponível em: <http://www.lume.ufrgs.br/ bitstream/handle/10183/16012/\%2000068 5618.pdP?sequence $=1>$. Acesso em: 20.mai.2013. 